Clinical and socioeconomic impact of moderate-to-severe versus mild influenza in children

\title{
Heikkinen, $T$.
}

2016-07

Heikkinen , T , Silvennoinen , H , Heinonen , S \& Vuorinen , T 2016 , ' Clinical and socioeconomic impact of moderate-to-severe versus mild influenza in children ' , European Journal of Clinical Microbiology \& Infectious Diseases , vol. 35 , no. 7 , pp. 1107-1113 . https://doi.org/10.1007/s100

http://hdl.handle.net/10138/224119

https://doi.org/10.1007/s10096-016-2641-9

publishedVersion

Downloaded from Helda, University of Helsinki institutional repository.

This is an electronic reprint of the original article.

This reprint may differ from the original in pagination and typographic detail.

Please cite the original version. 


\title{
Clinical and socioeconomic impact of moderate-to-severe versus mild influenza in children
}

\author{
T. Heikkinen ${ }^{1,2} \cdot$ H. Silvennoinen ${ }^{1} \cdot$ S. Heinonen ${ }^{1,5} \cdot$ T. Vuorinen $^{3,4}$
}

Received: 23 February 2016/Accepted: 28 March 2016 / Published online: 16 April 2016

(C) Springer-Verlag Berlin Heidelberg 2016

\begin{abstract}
Some studies have assessed the efficacy of influenza vaccination in children separately for moderate-to-severe and any influenza, but the definition used for identifying children with moderate-to-severe illness has not been validated. We analyzed clinical and socioeconomic data from two prospective cohort studies of respiratory infections among children aged $\leq 13$ years (four influenza seasons, 3,416 childseasons of follow-up). We categorized children with laboratory-confirmed influenza into two mutually exclusive groups of moderate-to-severe and mild influenza using the previously proposed criteria. We obtained the data for the analyses from structured medical records filled out by the study physicians and from daily symptom cards filled out by the parents. Of 434 cases of influenza, 217 (50\%) were classified as moderate-to-severe and $217(50 \%)$ as mild. The mean duration of fever was 4.0 days in children with moderate-to-severe influenza and 3.1 days in those with milder illness $(P<0.0001)$. Antibiotics were prescribed to $111(51 \%)$ children with moderate-to-severe and to ten (5\%) children with mild influenza $(P<0.0001)$. The rates of parental work absenteeism were 184 days per 100 children
\end{abstract}

T. Heikkinen

terho.heikkinen@utu.fi

1 Department of Pediatrics and Adolescent Medicine, Turku University Hospital, Turku, Finland

2 Department of Pediatrics, University of Turku, Kiinamyllynkatu 4-8, FI-20520 Turku, Finland

3 Department of Clinical Virology, Division of Microbiology and Genetics, Turku University Hospital, Turku, Finland

4 Department of Virology, University of Turku, Turku, Finland

5 Present address: Department of Pediatrics, Helsinki University Hospital, Helsinki, Finland with moderate-to-severe influenza and 135 days per 100 children with mild influenza $(P=0.02)$. The corresponding rates of children's own absenteeism from day care or school were 297 and 233 days respectively per 100 children $(P=0.006)$. Categorization of children into groups with moderate-tosevere and mild influenza is meaningful, and it identifies children in whom the clinical and socioeconomic impact of influenza is highest. Illness severity should be considered when assessing influenza vaccine effectiveness in children.

\section{Introduction}

Influenza places a high disease burden on children with respect to annual rates of infection, complications and hospitalizations [1-5]. The full burden of pediatric influenza extends beyond children themselves, for instance as parental work absenteeism because of child's influenza illness [6]. Children are also considered the main transmitters of influenza in the community [7, 8]. As a consequence, many health authorities and various expert groups in different countries currently recommend influenza vaccination of all children, not just of those with underlying medical conditions [5, 9-11].

The clinical presentation of influenza varies between different age groups but also within age groups [12, 13] Although virtually all children with influenza are febrile, and approximately half of them have fever $\geq 39.0^{\circ} \mathrm{C}$, not all children suffer a clinically severe illness. Although the ultimate aim of influenza vaccination is to prevent all influenza infections, it can be argued that prevention of the most severe forms of influenza would provide the greatest health and economic benefits to children, their families, and the society. However, there are few data to support this argument.

Clinical studies of influenza vaccines have conventionally assessed the efficacy of the vaccines against symptomatic 
laboratory-confirmed influenza, regardless of the severity of the disease. However, a few trials have determined the efficacy of influenza vaccination in children as a function of illness severity $[14,15]$. Recently, it was reported that the efficacy of an inactivated quadrivalent influenza vaccine was higher against moderate-to-severe influenza than against influenza of any severity in children [14]. This finding is intriguing and potentially of great importance for the development of influenza vaccination programs because it suggests that - from both the individual and the societal perspective - the effectiveness of influenza vaccination of children may be greater than previously anticipated. However, it remains to be shown whether the definition used for moderate-to-severe influenza is really meaningful and whether the clinical and socioeconomic outcomes in children with moderate-to-severe influenza are different from those associated with mild influenza. We designed this study to assess and compare various influenza-related health and socioeconomic outcomes between children with moderate-to-severe and mild influenza.

\section{Patients and methods}

\section{Study design and subjects}

We analyzed all data collected during two prospective cohort studies of respiratory infections among outpatient children in Turku, Finland. In both studies, the children were enrolled in the follow-up cohorts before the start of each respiratory season, and all children were eligible for participation, regardless of any underlying medical conditions. The first study was carried out during two consecutive winter seasons of 20002001 and 2001-2002 among children $\leq 13$ years of age, and it comprised 2,231 child-seasons of follow-up [1]. The second study was performed during the influenza seasons of 20072008 and 2008-2009 among children 1-3 years of age; this study comprised 1,185 children, 764 of whom were assessed for respiratory symptoms [16]. A proportion of children in the latter study were included in an embedded randomized placebo-controlled trial of oseltamivir treatment; the present analysis included only children who received placebo.

The original studies were approved by the Ethics Committee of the Hospital District of Southwest Finland, and they were conducted in accordance with the Declaration of Helsinki. Written informed consent was obtained from the parents or guardians of all participating children.

\section{Study conduct}

In both studies, the parents were asked to bring their child to the study clinic every time the child had fever or signs or symptoms of a respiratory infection. The study clinic was open every day, and all visits were free of charge to the parents. At each visit, the children were examined by a study physician who filled out a structured medical record containing the history, signs and symptoms, clinical findings, and treatment. Chest or sinus radiographs were routinely obtained for all children who were clinically suspected of having pneumonia or sinusitis. Pneumatic otoscopy, tympanometry and spectral-gradient acoustic reflectometry were used for diagnosing acute otitis media [17]. Children without any complications at the first visit were routinely reexamined after 57 days and whenever the parents deemed it necessary. The parents were provided with daily symptom diaries (for the entire season in the first study and for 21 days following each visit in the second one). The diaries consisted of daily charts inquiring about the symptoms of the child, the child's absence from day care or school because of respiratory illness, and parental absence from work because of the child's illness. The days of absenteeism included only actual days lost; days of illness occurring during free weekends or other days off were not recorded as causing absenteeism.

\section{Identification of influenza viruses}

During each episode of respiratory infection, regardless of the presence of fever or the severity of symptoms, nasal swabs were obtained from a depth of $2-3 \mathrm{~cm}$ in the nostril by use of a sterile cotton swab (first study) or flocked swab (second study). Detection of influenza A and B viruses in the specimens was primarily based on viral culture in Madin-Darby canine kidney cells and subsequent immunoperoxidase staining with monoclonal antibodies [18]. In the second study, in addition to viral culture, rapid influenza tests were used at the first visit; nasal swabs were subjected to antigen detection by means of time-resolved fluoroimmunoassay [19], and all swabs that remained negative for influenza with these methods were further tested with reverse-transcriptase polymerase chain reaction (RT-PCR) assays for influenza A and B viruses. All virologic assays were performed at the Department of Virology, University of Turku, Finland.

\section{Sources of data}

We obtained the data for this analysis from the structured medical records filled out by the study physicians at each visit to the study clinic, and from the daily symptom cards filled out by the parents.

\section{Definitions}

We divided all children with laboratory-confirmed influenza (either by viral culture, antigen detection, and/or RT-PCR) into two mutually exclusive groups: moderate-to-severe influenza and mild influenza. We identified children with moderate-tosevere influenza using the criteria previously published by 
Jain et al. [14]: body temperature $>39{ }^{\circ} \mathrm{C}$, physicianconfirmed acute otitis media, lower respiratory tract illness, or serious extrapulmonary complication. We classified all children who did not meet any of the above criteria as having mild influenza. We defined fever as temperature $>37.5^{\circ} \mathrm{C}$. When calculating the total duration of illness, we included all days on which the child had fever, rhinitis, or cough.

\section{Study outcomes}

We used the following primary outcomes: duration of fever, duration of any symptoms of influenza, antibiotic treatment, proportion of children with parental work absenteeism, duration of parental work absenteeism, proportion of children with absenteeism from day care or school, duration of children's absenteeism from day care or school, referral to emergency department, and hospitalization. We used the proportion of children with moderate-to-severe influenza in association with influenza A and B virus infections as a secondary outcome. In the primary analysis, we compared all outcomes between all children with moderate-to-severe and mild influenza. For a secondary analysis, we predefined all outcomes to be analyzed separately for subgroups of children $<3$ and $\geq 3$ years of age.

\section{Statistical analysis}

We divided the children into the age groups of $<3$ and $\geq 3$ years on basis of their age on the day when they made their first visit to the study clinic because of influenza. We used the $X^{2}$ test for comparing differences in proportions, and the unpaired $t$-test for comparing differences in means. We considered $P$ values $<0.05$ to indicate statistical significance. We performed all statistical analyses with StatsDirect, version 2.8.0 (StatsDirect).

\section{Results}

\section{Study participants}

Of a total of 437 children diagnosed with a virologically confirmed influenza illness, two children were excluded because of confirmed double viral infection and one child because of missing clinical data, leaving 434 children in the final analyses; 152 children $(35 \%)$ were $<3$ years of age and $282(65 \%)$ were 3-13 years of age. A total of 349 children $(80 \%)$ had influenza A (221 children with $\mathrm{A} / \mathrm{H} 1 \mathrm{~N} 1$ and 128 children with $\mathrm{A} / \mathrm{H} 3 \mathrm{~N} 2)$ and 73 children (17\%) had influenza B; in $12(3 \%)$ cases, the virus remained untyped.

\section{Children with moderate-to-severe and mild influenza}

Of all 434 cases of influenza, 217 (50\%) were classified as moderate-to-severe and 217 (50\%) as mild. Moderate-tosevere influenza occurred in $100(66 \%)$ of 152 children $<3$ years of age and in 117 (41\%) of 282 children 3-13 years of age (Table 1). The frequency of moderate-to-severe influenza was significantly higher $(64 \%)$ in children with influenza A/H3N2 than in those with $\mathrm{A} / \mathrm{H} 1 \mathrm{~N} 1(43 \% ; P=0.0002)$ or B $(44 \% ; P=0.005)$ infections.

Among the 217 children with moderate-to-severe influenza, fever $>39^{\circ} \mathrm{C}$ was present in $137(63 \%)$ children, whereas $80(37 \%)$ children were classified as moderate-to-severe cases because of acute otitis media or lower respiratory tract infection in the absence of high fever (Table 2). Of the 34 children with lower respiratory tract infection, $18(53 \%)$ had laryngitis, $8(24 \%)$ had pneumonia, and $8(24 \%)$ had expiratory wheezing. None of the children had a serious extrapulmonary complication of influenza.

\section{Antibiotic treatment}

Overall, 111 children (51\%) with moderate-to-severe influenza and ten children $(5 \%)$ with mild influenza were treated with antibiotics $(P<0.0001)$. Among children $<3$ years of age, 61 children $(61 \%)$ with moderate-to-severe influenza and none with mild influenza received antibiotics $(P$ $<0.0001)$. The corresponding figures in children $3-13$ years of age were $50(43 \%)$ and ten $(6 \%)$ respectively $(P<0.0001)$.

\section{Duration of fever and any illness symptoms}

Among all children, the mean duration of fever was 0.9 days longer in children with moderate-to-severe influenza (4.0 days) than in those with mild illness (3.1 days; $P<0.0001$; Table 3). A similar significant difference (3.9 vs 2.9 days; $P<0.0001)$ was observed among children $3-$ 13 years of age. In the age group $<3$ years, the mean duration of fever was 4.1 days in children with moderate-to-severe influenza and 3.6 days in those with mild illness $(P=0.17)$. The total duration of illness was 10.3 days in children with moderate-to-severe influenza and 9.4 days in those with mild disease $(P=0.06$; Table 3$)$.

\section{Parental work absenteeism}

Detailed data on absenteeism were available for 199 children (92\%) with moderate-to-severe and for 193 children (89\%) with mild influenza. Of these, 34 children who were cared for at home (22 children with moderate-to-severe and 12 with mild influenza) were excluded from the analyses of absenteeism. One of the parents had to stay off work for $\geq 1$ day in 103 (58\%) of 177 cases of moderate-to-severe influenza and in 88 
Table 1 Baseline characteristics of children with moderate-to-severe and mild influenza

\begin{tabular}{|c|c|c|c|c|c|c|}
\hline \multirow[t]{2}{*}{ Characteristic } & \multicolumn{2}{|l|}{$\begin{array}{l}\text { Age }<3 \text { years } \\
(n=152)\end{array}$} & \multicolumn{2}{|l|}{$\begin{array}{l}\text { Age } 3-13 \text { years } \\
(n=282)\end{array}$} & \multicolumn{2}{|l|}{$\begin{array}{l}\text { All children } \\
(n=434)\end{array}$} \\
\hline & $\begin{array}{l}\text { Moderate-to-severe } \\
(n=100)\end{array}$ & $\begin{array}{l}\text { Mild } \\
(n=52)\end{array}$ & $\begin{array}{l}\text { Moderate-to-severe } \\
(n=117)\end{array}$ & $\begin{array}{l}\text { Mild } \\
(n=165)\end{array}$ & $\begin{array}{l}\text { Moderate-to-severe } \\
(n=217)\end{array}$ & $\begin{array}{l}\text { Mild } \\
(n=217)\end{array}$ \\
\hline Girls & $43(43 \%)$ & $26(50 \%)$ & $49(42 \%)$ & $69(42 \%)$ & $92(42 \%)$ & $95(44 \%)$ \\
\hline Boys & $57(57 \%)$ & $26(50 \%)$ & $68(58 \%)$ & $96(58 \%)$ & $125(58 \%)$ & $122(56 \%)$ \\
\hline Child care at home & $16(16 \%)$ & $9(17 \%)$ & $6(5 \%)$ & $3(2 \%)$ & $22(10 \%)$ & $12(6 \%)$ \\
\hline Age, mean (SD), years & $2.0(0.5)$ & $2.2(0.6)$ & $5.8(2.6)$ & $6.5(2.8)$ & $4.1(2.7)$ & $5.5(3.1)$ \\
\hline
\end{tabular}

$S D$ standard deviation

(49 \%) of 181 cases of mild influenza in children $(P=0.07$; Table 4). The overall rates of parental work absenteeism were 184 (95\% confidence interval [CI], 153-215) days per 100 children with moderate-to-severe influenza and $135(95 \% \mathrm{CI}$, $109-161)$ days per 100 children with mild influenza $(P=0.02$; Table 5).

\section{Children's absenteeism}

A child missed day care or school for $\geq 1$ day in 137 (77\%) of 177 cases of moderate-to-severe influenza and in 133 (73\%) of 181 cases with mild influenza (Table 4). Among children who were absent for $\geq 1$ day, the mean duration of absence was significantly longer (3.8 days) in children with moderate-tosevere influenza than in those with mild illness (3.2 days; $P=0.003$; Table 5). The rates of children's own absenteeism were 297 (95\% CI, 261-332) days per 100 children with moderate-to-severe influenza and 233 (95\% CI, 204-261) days per 100 children with mild influenza $(P=0.006)$.

\section{Referral to emergency department and hospitalization}

Three ( $3 \%$ ) of 100 children $<3$ years of age with moderate-tosevere influenza were referred to the emergency department, and one of them was hospitalized. No referrals or hospitalizations occurred in any other groups of children.

\section{Discussion}

Our study demonstrates that the clinical and socioeconomic impact of moderate-to-severe influenza is substantially greater than that of mild influenza. Children with moderate-to-severe illness had a significantly longer duration of fever, and they received antibiotic treatment more frequently than children with mild influenza. Per every 100 children with influenza, the parents of children with moderate-to-severe illness lost approximately 50 more days of work than the parents of children with mild influenza, and an even greater difference was
Table 2 Clinical features of 217 children with moderate-to-severe influenza

\begin{tabular}{llll}
\hline Variable & \multicolumn{2}{l}{ Age group } & \\
\cline { 2 - 4 } & $<3$ years $(n=100)$ & $3-13$ years $(n=117)$ & All children $(n=217)$ \\
\hline Fever $>39^{\circ} \mathrm{C}$ & $57(57)$ & $80(68)$ & $137(63)$ \\
AOM & $62(62)$ & $43(37)$ & $105(48)$ \\
LRTI & $15(15)$ & $19(16)$ & $34(16)$ \\
Breakdown of criteria & & & \\
Fever $>39^{\circ} \mathrm{C}$ only & $29(29)$ & $58(50)$ & $87(40)$ \\
Fever $>39^{\circ} \mathrm{C}+$ AOM only & $22(22)$ & $17(15)$ & $39(18)$ \\
Fever $>39^{\circ} \mathrm{C}+$ LRTI only & $5(5)$ & $3(3)$ & $3(1)$ \\
Fever $>39^{\circ} \mathrm{C}+$ AOM + LRTI & $1(1)$ & $2(2)$ & $57(26)$ \\
AOM only & $34(34)$ & $23(20)$ & $17(8)$ \\
LRTI only & $4(4)$ & $13(11)$ & $6(3)$ \\
AOM + LRTI only & $5(5)$ & $1(1)$ & \\
\hline
\end{tabular}

$A O M$ acute otitis media, LRTI lower respiratory tract infection. Data are number (\%) of children 
Table 3 Duration of fever and any symptoms of influenza in children with moderate-to-severe and mild influenza

\begin{tabular}{|c|c|c|c|c|c|}
\hline \multirow[t]{2}{*}{ Variable, age group } & \multicolumn{2}{|c|}{ Moderate-to-severe influenza } & \multicolumn{2}{|c|}{ Mild influenza } & \multirow[t]{2}{*}{$P^{\mathrm{a}}$} \\
\hline & Mean (SD) & Median (IQR) & Mean (SD) & Median (IQR) & \\
\hline \multicolumn{6}{|c|}{ Duration of fever (days) ${ }^{b}$} \\
\hline$<3$ years & $4.1(2.1)$ & $4.0(3.0-5.0)$ & $3.6(2.0)$ & $4.0(2.0-5.0)$ & 0.17 \\
\hline $3-13$ years & $3.9(1.7)$ & $4.0(3.0-5.0)$ & $2.9(1.9)$ & $3.0(2.0-4.0)$ & $<0.0001$ \\
\hline All children & $4.0(1.9)$ & $4.0(3.0-5.0)$ & $3.1(1.9)$ & $3.0(2.0-4.0)$ & $<0.0001$ \\
\hline \multicolumn{6}{|c|}{ Duration of any symptoms (days) ${ }^{\mathrm{c}}$} \\
\hline$<3$ years & $12.1(4.8)$ & $12.0(8.0-15.0)$ & $11.0(5.3)$ & $10.0(7.0-13.0)$ & 0.24 \\
\hline $3-13$ years & $8.8(5.0)$ & $8.0(6.0-11.0)$ & $8.8(4.6)$ & $9.0(5.0-12.0)$ & 0.99 \\
\hline All children & $10.3(5.2)$ & $9.0(7.0-13.0)$ & $9.4(4.8)$ & $9.0(5.0-12.0)$ & 0.06 \\
\hline
\end{tabular}

observed with respect to the children's own absenteeism from day care or school between the groups.

To our knowledge, this is the first clinical study to assess various health and socioeconomic outcomes in children with influenza as a function of the severity of the illness. Our analyses were based on real-life data collected during prospective studies of children who were enrolled in the follow-up cohorts without using any exclusion criteria, whereby the children represented the normal pediatric population in the community. Furthermore, we obtained specimens for the detection of influenza viruses during each episode of respiratory illness, regardless of the severity of symptoms, which prevented any potential bias due to sampling, for example only children with more severe illnesses.

At first glance, our finding that the clinical and socioeconomic impact of moderate-to-severe influenza was higher than that of mild influenza may sound circular reasoning and trivial because many people might assume that this is obviously the case. However, there are no data to demonstrate that, for example, children initially presenting with high fever would automatically have a longer duration of illness or that their parents would lose more days of work. It is also important to emphasize that our study did not attempt to define the criteria for a severe influenza, but the purpose of our study was to assess and validate the criteria that were previously published by others and that were used for determining the efficacy of influenza vaccines separately for moderate-to-severe and mild influenza in children $[14,15]$. If the outcome of our analysis had been that the real-life impact of moderate-tosevere and mild influenza was similar, the conclusion would have been that categorization of children into these groups was arbitrary and that calculation of vaccine efficacy separately against milder and more severe forms of the disease would have no value from the viewpoint of the development of influenza vaccination programs.

Two recent studies have analyzed the efficacy of influenza vaccination in children according to illness severity. Jain et al. [14] reported that the efficacy of an inactivated quadrivalent
Table 4 Parental work absenteeism and children's absenteeism for $\geq 1$ day in cases of moderate-to-severe and mild influenza in children

\begin{tabular}{|c|c|c|c|c|c|}
\hline \multirow[t]{2}{*}{ Variable, age group } & \multicolumn{2}{|c|}{ Moderate-to-severe influenza } & \multicolumn{2}{|c|}{ Mild influenza } & \multirow[t]{2}{*}{$P^{\mathrm{a}}$} \\
\hline & $n / N$ & $\%$ & $n / N$ & $\%$ & \\
\hline \multicolumn{6}{|c|}{ Parental work absenteeism } \\
\hline$<3$ years & $49 / 77$ & 64 & $28 / 40$ & 70 & 0.49 \\
\hline $3-13$ years & $54 / 100$ & 54 & $60 / 141$ & 43 & 0.08 \\
\hline All children & $103 / 177$ & 58 & $88 / 181$ & 49 & 0.07 \\
\hline \multicolumn{6}{|c|}{ Children's absenteeism } \\
\hline$<3$ years & $58 / 77$ & 75 & $32 / 40$ & 80 & 0.57 \\
\hline $3-13$ years & $79 / 100$ & 79 & $101 / 141$ & 72 & 0.19 \\
\hline All children & $137 / 177$ & 77 & $133 / 181$ & 73 & 0.39 \\
\hline
\end{tabular}

$n / N$ number of parents or children with absenteeism/number of children with data available

${ }^{\text {a }}$ Chi-square test 
Table 5 Duration of parental and children's absenteeism in cases of moderate-to-severe and mild influenza in children

\begin{tabular}{|c|c|c|c|c|c|c|}
\hline \multirow[t]{2}{*}{ Variable, age group } & \multicolumn{3}{|c|}{ Mean duration of absence, days (SD) ${ }^{\mathrm{a}}$} & \multicolumn{3}{|c|}{ Total days of absence per 100 children $(95 \% \mathrm{CI})^{\mathrm{b}}$} \\
\hline & $\begin{array}{l}\text { Moderate-to-severe } \\
\text { influenza } \\
(n=177)\end{array}$ & $\begin{array}{l}\text { Mild influenza } \\
(n=181)\end{array}$ & $P^{\mathrm{c}}$ & $\begin{array}{l}\text { Moderate-to-severe } \\
\text { influenza } \\
(n=177)\end{array}$ & $\begin{array}{l}\text { Mild influenza } \\
(n=181)\end{array}$ & $P^{\mathrm{c}}$ \\
\hline \multicolumn{7}{|c|}{ Parental work absenteeism } \\
\hline$<3$ years & $3.7(2.0)$ & $3.1(1.6)$ & 0.17 & $236(182-290)$ & $218(154-281)$ & 0.67 \\
\hline $3-13$ years & $2.7(1.5)$ & $2.6(1.5)$ & 0.86 & $144(110-178)$ & $111(84-138)$ & 0.13 \\
\hline All children & $3.2(1.8)$ & $2.8(1.5)$ & 0.11 & $184(153-215)$ & $135(109-161)$ & 0.02 \\
\hline \multicolumn{7}{|c|}{ Children's absenteeism } \\
\hline$<3$ years & $4.1(2.1)$ & $3.8(1.9)$ & 0.43 & $312(254-370)$ & $303(229-376)$ & 0.85 \\
\hline $3-13$ years & $3.6(2.0)$ & $3.0(1.4)$ & 0.02 & $285(240-330)$ & $213(183-243)$ & 0.009 \\
\hline All children & $3.8(2.0)$ & $3.2(1.6)$ & 0.003 & $297(261-332)$ & $233(204-261)$ & 0.006 \\
\hline
\end{tabular}

vaccine among children 3-8 years of age was $59.3 \%$ for influenza of any severity but $74.2 \%$ for moderate-to-severe influenza. Using the same definition for severity, Ambrose et al. [15] assessed the efficacy of live attenuated influenza vaccine in children 2-5 years of age during two consecutive seasons and found no differences in vaccine efficacy between children with moderate-to-severe (88.5-95.4\%) and milder illnesses (84.2-91.4\%).

In our study, several outcomes were significantly different between the moderate-to-severe and mild groups in the primary analysis that included all children, but not when analyzed separately for children $<3$ years of age. This could be partly explained by reduced power due to smaller numbers of children in the subgroup analyses. However, because the signs and symptoms of influenza vary between different age groups [12], it is possible that alternative definitions of moderate-tosevere illness could work better for identifying young children in whom the clinical and socioeconomic consequences of influenza are more extensive.

Because children are the main disseminators of influenza viruses in the community $[7,8]$, prevention of even the milder illnesses in children would be important for reducing the transmission of influenza to other age groups, e.g., to the vulnerable elderly population. However, it is without doubt that the more severe cases of pediatric influenza place the greatest burden on the children and their families, and prevention of these illnesses would be most beneficial from the clinical, social, and economic perspectives. Prevention of influenza is particularly important but also challenging for the youngest children, in whom the clinical presentation of influenza is most severe and the rates of influenza-associated complications and hospitalizations are highest $[1,5,12,20]$. Although the relative efficacy of inactivated versus live attenuated influenza vaccines has been a topic for discussion during the past seasons [21, 22], it is good to notice that the inactivated vaccine is the only option for use in children $<2$ years of age.

In conclusion, our study shows that categorization of influenza infections in children into milder and more severe forms of the illness is meaningful and enables identification of children in whom the overall clinical and socioeconomic burden of influenza is greatest. The approach of assessing vaccine efficacy separately against all versus severe illnesses has already been used for some vaccines, e.g., varicella and rotavirus vaccines, for which the highest effectiveness has been demonstrated against the most severe forms of the illnesses [23-25]. Although the definition of moderate-to-severe influenza may still be subject to further improvement, our results strongly support the inclusion of illness severity as a key factor in future studies assessing the effectiveness of influenza vaccination in children.

Acknowledgments We are indebted to all study physicians, nurses, and laboratory personnel involved in the performance of the follow-up studies for their invaluable contributions.

\section{Compliance with ethical standards}

Funding This work was supported by GlaxoSmithKline Biologicals $\mathrm{SA}$, which provided a grant for investigator-initiated epidemiologic studies of influenza to the Hospital District of Southwestern Finland (a secondary employer of T.H.).

Conflicts of interest T.H. has been a consultant to GlaxoSmithKline, Novartis, Sanofi Pasteur, and Sanofi Pasteur MSD, and has given lectures at academic symposia organized by AbbVie and Sanofi Pasteur. All other authors declare that they have no conflict of interest. 
Ethical approval The original studies were approved by the Ethics Committee of the Hospital District of Southwest Finland, and they were conducted in accordance with the Declaration of Helsinki.

Informed consent Written informed consent was obtained from the parents or guardians of all participating children.

\section{References}

1. Heikkinen T, Silvennoinen H, Peltola V, Ziegler T, Vainionpää R, Vuorinen $\mathrm{T}$ et al (2004) Burden of influenza in children in the community. J Infect Dis 190:1369-1373

2. Poehling KA, Edwards KM, Weinberg GA, Szilagyi P, Staat MA, Iwane MK et al (2006) The underrecognized burden of influenza in young children. N Engl J Med 355:31-40

3. Heikkinen T (2006) Influenza in children. Acta Paediatr 95:778784

4. Fraaij PLA, Heikkinen T (2011) Seasonal influenza: the burden of disease in children. Vaccine 29:7524-7528

5. Heikkinen T, Tsolia M, Finn A (2013) Vaccination of healthy children against seasonal influenza: a European perspective. Pediatr Infect Dis J 32:881-888

6. Salo H, Kilpi T, Sintonen H, Linna M, Peltola V, Heikkinen T (2006) Cost-effectiveness of influenza vaccination of healthy children. Vaccine 24:4934-4941

7. Reichert TA, Sugaya N, Fedson DS, Glezen WP, Simonsen L, Tashiro M (2001) The Japanese experience with vaccinating schoolchildren against influenza. N Engl J Med 344:889-896

8. Loeb M, Russell ML, Moss L, Fonseca K, Fox J, Earn DJD et al (2010) Effect of influenza vaccination of children on infection rates in Hutterite communities: a randomized trial. JAMA 303:943-950

9. Grohskopf LA, Sokolow LZ, Olsen SJ, Bresee JS, Broder KR, Karron RA (2015) Prevention and control of influenza with vaccines: recommendations of the Advisory Committee on Immunization Practices, United States, 2015-16 influenza season. MMWR 64:818-825

10. Heikkinen T, Booy R, Campins M, Finn A, Olcén P, Peltola H et al (2006) Should healthy children be vaccinated against influenza? A consensus report of the Summits of Independent European Vaccination Experts. Eur J Pediatr 165:223-228

11. Usonis V, Anca I, André F, Chlibek R, Ivaskeviciene I, Mangarov A et al (2010) Central European Vaccination Advisory Group (CEVAG) guidance statement on recommendations for influenza vaccination in children. BMC Infect Dis 10:168

12. Silvennoinen $H$, Peltola V, Lehtinen $P$, Vainionpää R, Heikkinen $T$ (2009) Clinical presentation of influenza in unselected children treated as outpatients. Pediatr Infect Dis J 28:372-375
13. Silvennoinen H, Peltola V, Vainionpää R, Ruuskanen $\mathrm{O}$, Heikkinen $\mathrm{T}$ (2012) Admission diagnoses of children 0-16 years of age hospitalized with influenza. Eur J Clin Microbiol Infect Dis 31:225231

14. Jain VK, Rivera L, Zaman K, Espos RA Jr, Sirivichayakul C, Quiambao BP et al (2013) Vaccine for prevention of mild and moderate-to-severe influenza in children. N Engl J Med 369: 2481-2491

15. Ambrose CS, Wu X, Caspard H, Belshe RB (2014) Efficacy of live attenuated vaccine against influenza illness in children as a function of illness severity. Vaccine 32:5546-5548

16. Heinonen S, Silvennoinen H, Lehtinen P, Vainionpää R, Vahlberg T, Ziegler T et al (2010) Early oseltamivir treatment of influenza in children 1-3 years of age: a randomized controlled trial. Clin Infect Dis 51:887-894

17. Puhakka T, Pulkkinen J, Silvennoinen H, Heikkinen T (2014) Comparison of spectral gradient acoustic reflectometry and tympanometry for detection of middle ear effusion in children. Pediatr Infect Dis J 33:e183-186

18. Waris M, Ziegler T, Kivivirta M, Ruuskanen O (1990) Rapid detection of respiratory syncytial virus and influenza A virus in cell cultures by immunoperoxidase staining with monoclonal antibodies. J Clin Microbiol 28:1159-1162

19. Nikkari S, Halonen P, Kharitonenkov I, Kivivirta M, Khristova M, Waris $M$ et al (1989) One-incubation time-resolved fluoroimmunoassay based on monoclonal antibodies in detection of influenza A and B viruses directly in clinical specimens. J Virol Methods 23:29-40

20. Silvennoinen H, Peltola V, Vainionpää R, Ruuskanen O, Heikkinen $\mathrm{T}$ (2011) Incidence of influenza-related hospitalizations in different age groups of children in Finland: a 16-year study. Pediatr Infect Dis J 30:e24-28

21. Belshe RB, Edwards KM, Vesikari T, Black SV, Walker RE, Hultquist $\mathrm{M}$ et al (2007) Live attenuated versus inactivated influenza vaccine in infants and young children. N Engl J Med 356:685696

22. Advisory Committee on Immunization Practices (2015) Summary report: February 26, 2015. Washington, DC: Department of Health and Human Services, CDC. Available at: http://www.cdc.gov/ vaccines/acip/meetings/downloads/min-archive/min-2015-02.pdf. Accessed 4 January 2016

23. Seward JF, Marin M, Vázquez M (2008) Varicella vaccine effectiveness in the US vaccination program: a review. J Infect Dis 197: S82-89

24. Liese JG, Cohen C, Rack A, Pirzer K, Eber S, Blum M et al (2013) The effectiveness of varicella vaccination in children in Germany: a case-control study. Pediatr Infect Dis J 32:998-1004

25. Vesikari T, Van Damme P, Giaquinto C, Dagan R, Guarino A, Szajewska H, Usonis V (2015) European Society for Paediatric Infectious Diseases consensus recommendations for rotavirus vaccination in Europe: update 2014. Pediatr Infect Dis J 34:635-643 